\title{
THE INFLUENCE OF INTER-IMPLANT DISTANCE ON BONE HEIGHT CHANGES FOR A THREE IMPLANT RETAINED MANDIBULAR TELESCOPIC OVERDENTURE
}

\author{
Nouran Abdel Nabi*
}

\begin{abstract}
Introduction: Implant retained mandibular overdentures have improved patient satisfaction and quality of life for completely edentulous patients , that is why it has been the most successful treatment modality for the edentulous mandible. The optimum number of implants to retain an overdenture has been debatable, most studies have recommended installing two to four implants to retain an overdenture. Many authors have reported that three implant retained over denture will provide sufficient support and stability. Bars, studs, magnets, and telescopic coping are attachments to be used to retain mandibular overdentures, many factors should be considered during the selection of the most suitable attachment. Telescopic retainers have offered excellent retention with a splinting effect in addition to providing superior oral hygiene maintenance. One of the important criteria determining the success of an overdenture is the even distribution of stresses to the underlying implants as excessive loads may result in failure of the anchoring implants. Monitoring of bone height changes is therefore mandatory and is most commonly carried out by standardized peri-apical X-rays at different follow up intervals. The aim of this clinical trial is to investigate the effect of the inter-implant distance in a telescopic three implant retained overdenture on the amount of load transfer to the implants which is clinically interpreted by changes in bone height utilizing standardized peri-apical $\mathrm{x}$ rays.
\end{abstract}

Materials and methods: Fourteen completely edentoulous patients have been recruited from the outpatient clinic of the Removable Prosthodontic Department Cairo University. All recruited patients were seeking implant installation in the edentulous jaw to improve retention of their mandibular denture. Patients with contra-indication for implant placement were excluded from the study. All patients received three implants in the mandible in the canine region bilaterally and in the central incisor area, but the interimplant distance of the installed implants varied in the two groups of patients. In the first group of patients all implants were installed with an even interimplant distance of $40 \mathrm{~mm}$. While in the second group of patients an uneven distribution of implants with different interimplant distance, on the right side the implants in the canine area and central incisor region had an interimplant distance of $15 \mathrm{~mm}$, while on the left side the implant in the left canine region was installed at a $40 \mathrm{~mm}$ from the implant at the central incisor area. Standardized peri-apical $\mathrm{x}$ rays were used to record changes in bone height for the three installed implants in the two groups of patients at the different follow up intervals; day of delivery, after 3 month follow up, after 6 month follow up and after 12 month follow up.

* Lecturer of Removable Prosthodontics. Cairo University 
Results: In both groups of patients there has been a decrease in bone height for all implants after a 12 month follow up. In the first group of patients there was no statistically significant difference in the mean bone height changes between the three implants, but the implant in the mid line have shown the greatest changes in bone height followed by the implant in the left canine and the least was the implant in the right side. In the second group of patients there was no statistically significant difference between the two implants in the right side with a $15 \mathrm{~mm}$ interimplant distance, while a statistically significant difference in bone height changes was recorded for the implant on the left side with a $40 \mathrm{~mm}$ interimplant distance showing the greatest changes in bone height followed by the implant in the mid line, and the least was the implant in the right canine. When comparing the mean bone height changes between the two groups of patients after a 12 month follow up, the second group of patients have shown a statistically significant decrease in bone height for all of the three implants, indicating more bone loss encountered in the second group of patients than in the first group.

Conclusion: The interimplant distance plays an important role in the transfer of stresses to the anchoring implants, as the interimplant distance increase so will the lever arm and eventually the moment falling on the implant will also increase, which will lead to bone height changes around the installed implants. All of the bone height changes in the present study after a 12 month follow up were within the physiological limit. Within limitations of this clinical trial it is recommended to install implants with an equal interimplant distance, and avoid implant installation with an increased interimplant distance. More researches with a larger sample size and longer follow ups are recommended to reach to definitive conclusions.

\section{INTRODUCTION}

Completely edentulous patients have been suffering from lack of retention and stability of their mandibular complete dentures that affected their ability to carry out a lot of functions and also had an impact on their appearance that have all led to a decline in patient satisfaction and quality of life. Recently implant retained overdentures have been selected as the first treatment option for completely edentulous patients especially in the mandibular $\operatorname{arch}^{1,2}$. Implant retained mandibular overdenture have reported greater patient satisfaction, improvement in speech, mastication and quality of life when compared with conventional mandibular dentures $^{3}$. The main advantages of overdentures is the reduction in the number of installed implants using simplified surgical techniques and also making use of prefabricated attachments have made the prosthetic phase carried out easily ${ }^{4}$.

Two to four implant retained mandibular overdentures have been reported to be a successful treatment option for the edentulous jaw ${ }^{5}$. Two implant retained mandibular retained overdenture have been considered the standard of care according to the Mc Gill Consensus 20026 , and many studies have reported that two implants would result in satisfactory retention and support for overdentures ${ }^{1,2,7}$. Some studies have proven that there is no difference in the clinical and radio graphical state of patients having two and four implants installed to retain an over denture ${ }^{8-12}$. While on the other hand installation of three or more implants have improved retention and resulted in an angular relationship instead of a straight line relationship ${ }^{13}$. In a three implant retained over denture, the most anterior implant would provide indirect retention for the overdenture by preventing the intrusion of the anterior segment of the denture in a tissue ward direction ${ }^{13}$. Many studies $^{14-16}$ have reported the use of three implants, and have indicated that more than two implants would be used to retain mandibular overdentures in cases that would require optimum retention, cases with high 
muscle attachment, prominent mylohyiod ridges and patients with increased gaging sensation ${ }^{17}$.It could be concluded that the optimum number of implants required to retain an overdenture in the mandible is still debatable.

Implant retained overdenture attachments can be classified into; bars, studs, magnets, and telescopic copings ${ }^{18}$.The selection of the appropriate kind of attachment will depend upon many factors; morphology of the alveolar ridge, high muscle attachment and specific patient related factors ${ }^{17}$. In addition to the amount of retention needed, mastication, and cost are important factors that would influence the selection of any attachment. Telescopic retainers would mainly consist of a primary and secondary coping. Telescopic retainers have reported to provide excellent retention resulting from the frictional fit between the primary and secondary coping. In addition to the circumferential relation between the outer and inner copings that have resulted in better force distribution with axial transfer of occlusal forces resulting in decreased torque to the underlying abutments ${ }^{1920}$. Telescopic retainers apart from providing better retentive and stabilizing properties with a splinting action ${ }^{19,20}$ they also provide excellent oral hygiene maintenance ${ }^{19}$ it has been stated that telescopic retainers used in overdentures have been given the name of "Periooverdentures" due to their excellent accessibility for cleaning thus preventing the incidence of hyperplasia and peri-implantitis ${ }^{\mathbf{2 1}}$.

One of the parameters that would guide the success of overdenture prosthesis is the amount of stresses that are distributed to the implants, as bone resorption may be stimulated around implants that are subjected to excessive loads ${ }^{22,23}$. Therefore when planning for an overdenture the number ${ }^{5}$, diameter ${ }^{24}$, length ${ }^{24}$, location ${ }^{25}$, distribution and inclination ${ }^{26}$ of the implants should be carefully considered. Many studies, 5,911,22-26 have reported the ideal number, location and position of the implants and attachments to be used in an overdenture prosthesis but still this issue seems to be of high controversy. There is also a lack in research concerning the influence of the inter-implant distance on the load transfer to the implants.

One of the long term clinical evaluation of the implants used to support an overdenture is monitoring of the marginal bone level around the implants. Changes in marginal bone levels that are beyond the physiologic limits would result in loss of bone height around the anchoring implant. Bone loss of around $1.5 \mathrm{~mm}$ after the first year of loading with an additional $0.2 \mathrm{~mm}$ amount of bone loss per year is considered to be within the physiologic limits ${ }^{27-29}$. The evaluation of changes in bone height around the implants can be carried out by comparing standardized peri-apical $\mathrm{x}$-rays at different intervals.

The aim of this clinical trial is to investigate the effect of the inter-implant distance in a telescopic three implant retained overdenture on the amount of load transfer to the implants which is clinically interpreted by changes in bone height utilizing standardized peri-apical $\mathrm{x}$ rays.

\section{MATERIALS AND METHODS}

Fourteen completely edentulous patients were recruited from the outpatient clinic of Removable Prosthodontics Cairo University. All patients recruited were seeking to install implants in their lower jaw, and have to meet the following inclusion criteria: age ranging from 50 to 69 years old, patients should have no contra-indication for implant installation, all patients should perform a glycosylated hemoglobin analysis and only up to 8 were included in the study. All patients had to sign an informed consent before the start of the study, and have to comply with the assigned follow-ups. Patients with any contraindications for implant placement or those who didn't comply with the follow ups were excluded from the study. 
All patients included had maxillary and mandibular complete dentures fabricated following the conventional steps, after a period of 6 weeks adaptation, all patients were ready for implant installation. The lower denture was duplicated into a radiographic stent, having radio-opaque markers in the areas of implant installation. All patients had a CBCT $\mathrm{x}$ ray wearing the radiographic stent, to allow for proper implant planning and to visualize the height and width of the osteotomy site. The radiographic stent was then modified to a surgical stent by making a tunnel corresponding to the site of implant installation.

All Patients in this study received three implants in the lower jaw, in the first group of patients the implants were installed in the canine area bilaterally, and one implant in the mid line, which was slightly anterior to the two distal implants giving a tripod distribution. The distance between the three implants was $40 \mathrm{~mm}$. While in the second group of patient, the implants on the right side were installed in the canine area, and in the central incisor area having an interimplant distance of $15 \mathrm{~mm}$, while the third implant was placed in the first premolar area at a 40mm distance from the central incisor area. All patients were randomly divided into two groups by using sealed envelopes during implant installation. All of the implants in both groups were installed using the surgical stent with accurate measurement of the inter-implant distance.

At the day of surgery all patients were instructed to take $2 \mathrm{gm}$ of amoxicillin 2 hours before surgery. All implants used in this study was Implant Direct*, of width $3.7 \mathrm{~mm}$ and length $11.5 \mathrm{~mm}$, drilling was carried out following the implant manufacturer instructions. Suturing was then carried out, and the patient denture was modified using a soft liner at the day of surgery, patients were recalled after 7 days for suture removal.

A delayed (conventional) loading protocol was followed in this study and all patients were recalled after 3 month from implant installation for a second stage surgery, healing abutments were screwed and left for ten days for proper healing.

After proper healing, a lower primary impression was made using alginate impression material, and a stone cast was poured identifying the areas of the healing abutments. Corresponding to the areas of healing abutments, three layers of pink wax was placed over each healing abutment to simulate the height of the transfer coping. A special tray was then fabricated having an increased height anteriorly (height of the pink wax) to accommodate for the transfer copings during impression making. The healing abutment was removed and a transfer coping was screwed to all implants in both groups of patients. A closed tray impression was made for all patients, using a medium impression material ${ }^{* *}$, and then the implant analogue was screwed to each transfer coping and the tissue mimic material was injected around each implant and the cast was poured into an extra hard stone cast.

The transfer copings were then removed and the abutments were screwed to each implant. All abutments were being milled to be parallel to each other using a milling machine. Over each abutment a secondary coping was fabricated by building up of a layer of wax having the same shape of each abutment, and then this wax built up was casted into chrome-cobalt.

The primary coping in this study was considered to be the abutment, and the secondary coping was made of chrome-cobalt. The abutments were then screwed in the patient's mouth, and the secondary coping was checked for proper seating and placed on top of the abutment (Fig 1 A \&B). The patient's denture in both groups were modified by drilling three holes corresponding to the site of the abutment with the secondary copings. A soft mix of self-cure acrylic resin placed through the three corresponding holes and the patient was asked to bite in centric relation. After setting of the self-cure acrylic resin,

\footnotetext{
* Screw plant Implants, Implant direct TM LLC Spectra- system Dental implants , 27030 Malibu Hills , USA

** ImpregumTM ,PentaTM , 3M ESPE, Poly ether impression material, Seefeld, Germany.
} 


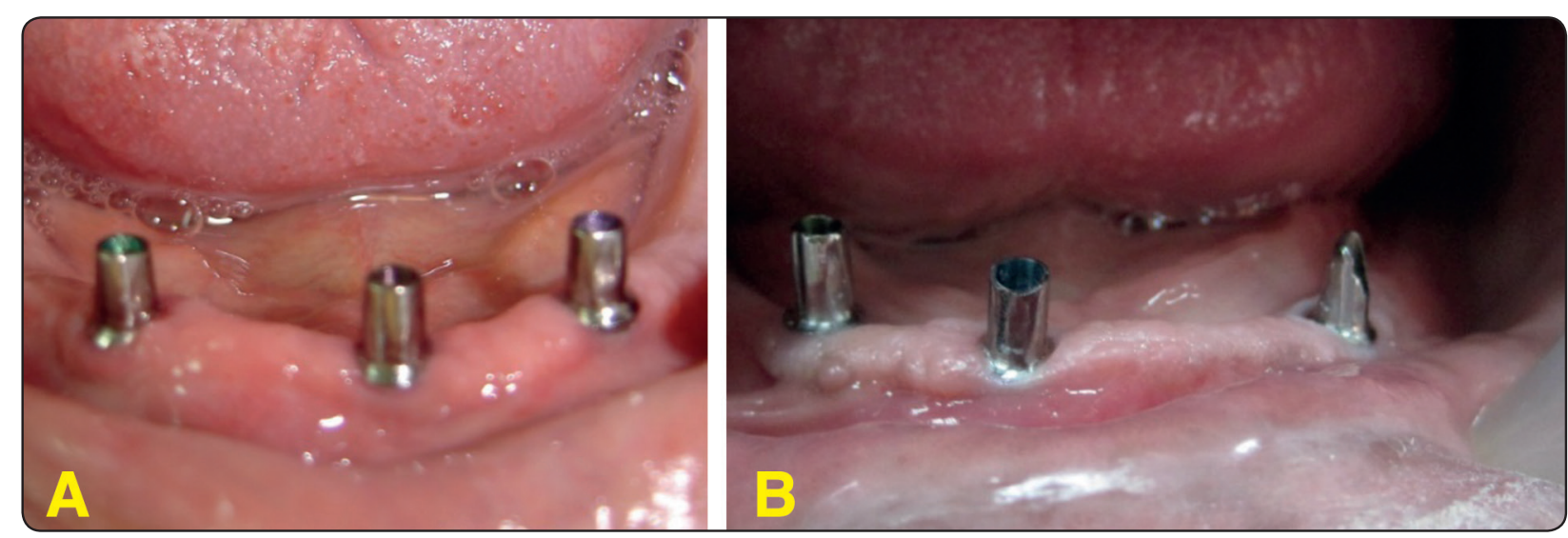

Fig. (1) A) first group of patient's B) Second group of patients

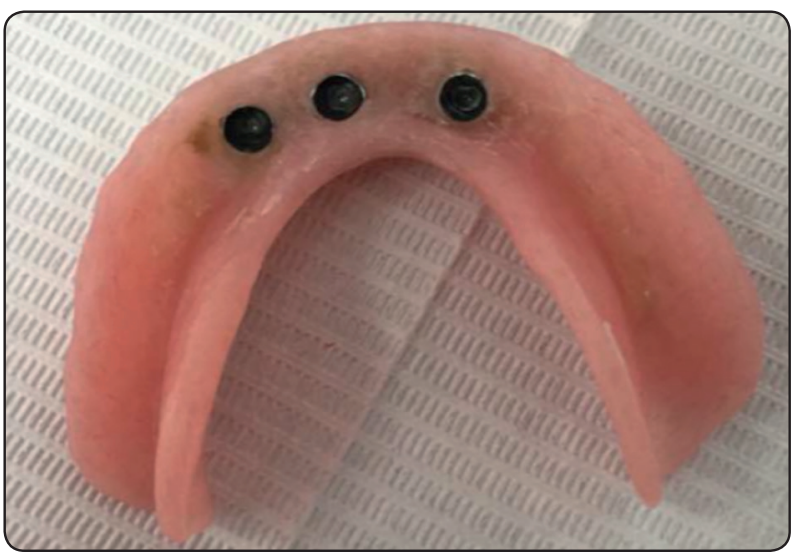

Fig. (2) Fitting surface of the denture after pick up

the three chrome-cobalt secondary copings were embedded in the fitting surface of the denture (Fig 2). The lower denture was polished, and then the patient was recalled after 3 days to check for any pressure areas or any adjustment in occlusion.

At the day of prosthesis delivery standardized peri-apical x-rays were recorded for both groups of patients. Standardized peri-apical $\mathrm{x}$ rays were carried out using the parallel technique, by using the bite block of the Rinn XCP set*. Rinn XCP set consists of a bite block (film holder) and an extraoral collimator ring that is parallel to the film holding

\footnotetext{
* Rinn XCP manufactures C. Ligin, III, USA.

** Ghenesyl addition silicone impression material, Italy. *** Digora computerized system, Helsinki, Finland.
}

plane of the $\mathrm{x}$-ray film holder. The bite block is used to hold the sensor (film), and the extra-oral collimator ring is used to direct the cone. Addition silicon impression material ${ }^{* *}$ was placed on the top and bottom of the bite block (Fig 3a), and the patient was asked to bite on the bite block resulting in an index that was securely attached to the bite block (Fig 3b). Each patient has his own bite block which was saved in his file. The Digora software*** was then used to measure bone height changes on the mesial and distal surface of each implant.

The Digora software was then used to measure bone height changes on the mesial and distal surface of each implant. The implant in the peri-apical $\mathrm{x}$ ray was calibrated by drawing a line from the junction of the implant and abutment to the apical end of the implant, this line was the calibration line corresponding to the implant real length which was $11.5 \mathrm{~mm}$. After the implant was calibrated, a line was drawn on each implant surface; at the mesial and distal surface starting from the first implant thread to bone contact to the apical implant thread to bone contact. The line drawn would correspond to the bone height on each surface (Fig $4 \mathbf{a}, \mathbf{b}$ ). Two blinded operators have carried out the assessment of bone height changes in order to have accurate results. 


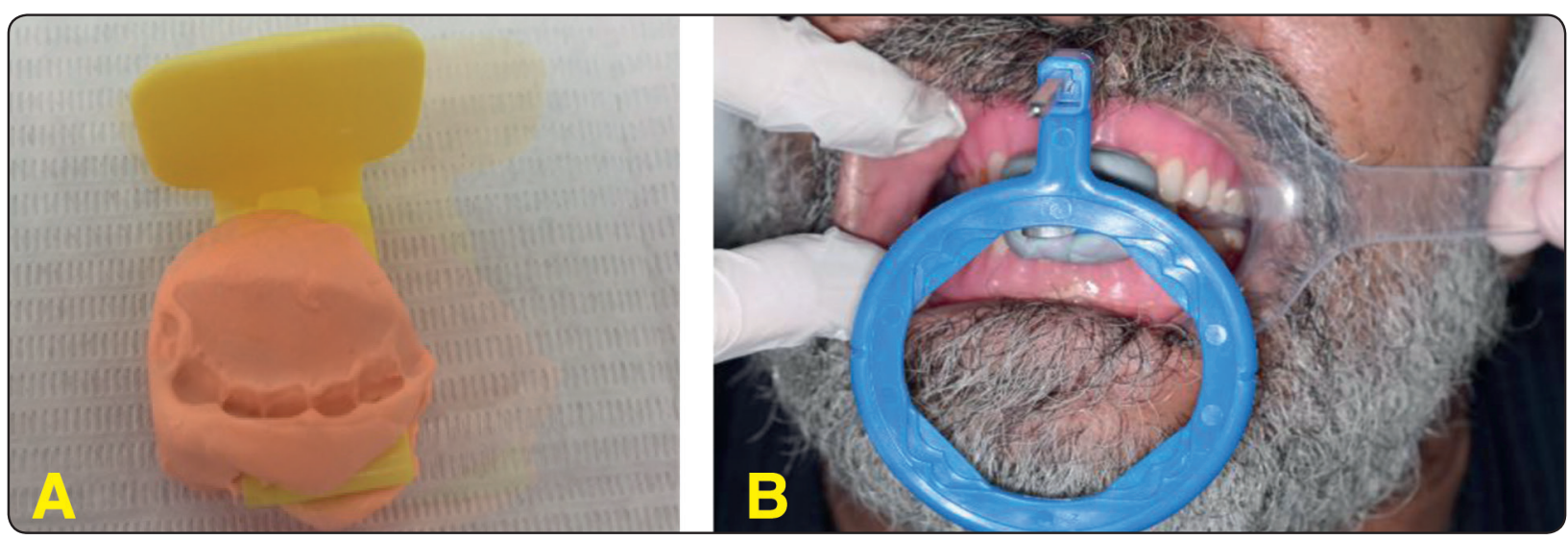

Fig. (3) A) Putty index on bite block B) Patient biting on the putty index

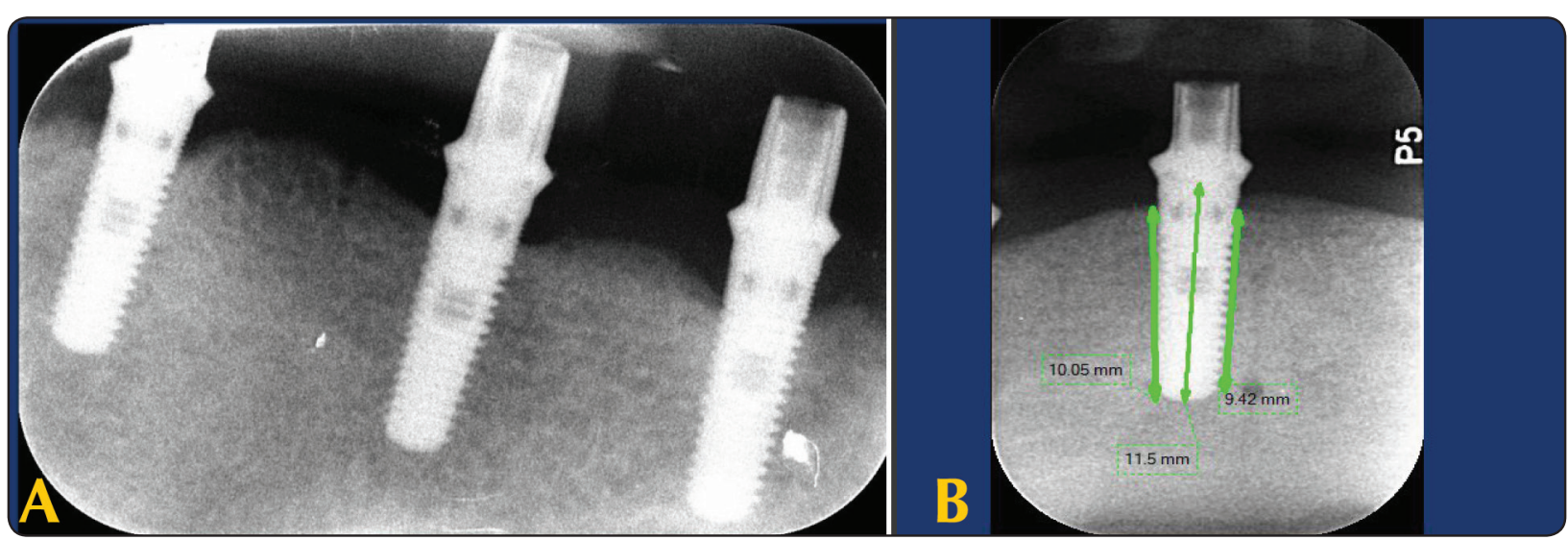

Fig. (4) A) Three implants on the per apical x ray film. B) bone height changes on each surface.

Bone height changes were recorded at the day of delivery, after 3 month, then after 6 month and finally after 12 month from delivery (loading).

\section{RESULTS}

The mean and standard deviation values were calculated for each group in each test. Data were explored for normality using Kolmogorov-Smirnov and Shapiro-Wilk tests. Data showed normal distribution (Parametric).

Independent sample t-test was used to compare between two groups in non-related samples. Repeated measure was used to compare between more than two groups in related samples. Paired sample t-test was used to compare between two groups in related samples. One-way ANOVA was used to compare between more than two groups in non-related samples.

The significance level was set at $\mathrm{P} \leq 0.05$. Statistical analysis was performed with IBM® SPSS ${ }^{\circledR}$ Statistics Version 20 for Windows.

When comparing the mean bone height changes between the three implants; Right canine (R3), Mid line implant, and the Left canine (L3), in each group at the different follow up intervals; at delivery, after 3 month, after 6 month and after 12 month from implant loading it was found that in the first group of patients there was no statistically significant difference with in bone height changes between the three implants in each of the follow up 
interval. In the first group of patients the mean bone height has declined for all three implant during all of the different follow ups recording $9.88 \mathrm{~mm} \pm 0.08$ for implant R3 at the day of delivery, and for the implant at the mid line was $9.2 \mathrm{~mm} \pm 0.46$, and for implant L3 it was recorded to be $9.77 \mathrm{~mm} \pm 0.12$ at the day of delivery, while after 12 month follow up, implant R3 mean bone height has decreased to $9.5 \mathrm{~mm} \pm 0.25$ where $p=0.114$ showing no significant difference when compared to the different follow up intervals, and the bone height for the implant at the mid line decreased to $8.67 \mathrm{~mm} \pm 0.32$ with a non-statistically significant difference between the different follow ups with $p=0.113$, and L3 showed also a decrease in bone height to $9.2 \mathrm{~mm} \pm 0.50$ and a non-significant difference of $p=0.230$. This all indicating that most of the bone changes have occurred around the implant in the mid line, as it has recorded the greatest decrease in bone height measurements when compared to implant R3 and

\section{L3. (Table 1)}

While in the second group of patients when comparing the mean bone height changes between the three implants at the different follow up intervals, it was found that there was no statistically significant difference between implant R3 and the implant at the mid line, while a statistically significant difference in the mean bone height changes was found when comparing that of implant R3 and the implant in the mid line, with implant L3 thought out all of the different follow up intervals. At delivery the mean bone height of implant R3 and the implant in the mid line was; $8.18 \mathrm{~mm} \pm 0.20$, and $8.13 \mathrm{~mm} \pm$ 0.21 , with a non-significant difference of $\mathrm{p}=0.971$. while for L3 the mean bone height was $7.47 \mathrm{~mm} \pm$ 0.35 with a statistically significant difference when compared to Implant R3 and the implant at the mid line with a $p=0.027$ at the day of delivery. After the 12 month follow up the mean bone height has decreased in implant R3 to $7.83 \mathrm{~mm} \pm 0.15$, and for the implant in the mid line the mean bone height has also decreased to $7.58 \mathrm{~mm} \pm 0.34$ with also a non-statistically significant difference in mean bone height changes between implant R3 and implant at the mid line having $p=0.591$. At implant L3 bone height has greatly shown a decrease to $6.9 \mathrm{~mm} \pm$ 0.36 , indicating a significant bone height change that mostly have occurred around the most distal implant L3, showing a statistically significant difference of $p=0.021$ when comparing the mean bone height changes to both implants R3 and that at the mid line (Table 1).

TABLE (1) The mean, standard deviation (SD) values of bone height changes in implants within each group for each time period.

\begin{tabular}{|c|c|c|c|c|c|c|c|c|c|c|c|c|c|c|c|c|}
\hline \multirow{4}{*}{ Variables } & \multicolumn{16}{|c|}{ Bone height Changes } \\
\hline & \multicolumn{8}{|c|}{ Group 1} & \multicolumn{8}{|c|}{ Group 2} \\
\hline & \multicolumn{2}{|c|}{ At delivery } & \multicolumn{2}{|c|}{$\begin{array}{l}\text { After } 3 \\
\text { months }\end{array}$} & \multicolumn{2}{|c|}{$\begin{array}{l}\text { After } 6 \\
\text { months }\end{array}$} & \multicolumn{2}{|c|}{$\begin{array}{c}\text { After } 12 \\
\text { months }\end{array}$} & \multicolumn{2}{|c|}{ At delivery } & \multicolumn{2}{|c|}{$\begin{array}{l}\text { After } 3 \\
\text { months }\end{array}$} & \multicolumn{2}{|c|}{$\begin{array}{l}\text { After } 6 \\
\text { months }\end{array}$} & \multicolumn{2}{|c|}{$\begin{array}{c}\text { After } 12 \\
\text { months }\end{array}$} \\
\hline & Mean & SD & Mean & SD & Mean & SD & Mean & SD & Mean & SD & Mean & SD & Mean & SD & Mean & SD \\
\hline $\begin{array}{c}\text { R3 } \\
\text { implant }\end{array}$ & $9.88^{\mathrm{a}}$ & 0.08 & $9.77^{\mathrm{a}}$ & 0.12 & $9.69^{\mathrm{a}}$ & 0.16 & $9.53^{\mathrm{a}}$ & 0.25 & $8.18^{\mathrm{a}}$ & 0.20 & $8.07^{\mathrm{a}}$ & 0.15 & $7.99^{a}$ & 0.12 & $7.83^{\mathrm{a}}$ & 0.15 \\
\hline $\begin{array}{c}\text { Mid } \\
\text { implant }\end{array}$ & $9.20^{\mathrm{a}}$ & 0.46 & $9.05^{\mathrm{a}}$ & 0.48 & $8.87^{\mathrm{a}}$ & 0.45 & $8.67^{\mathrm{a}}$ & 0.32 & $8.13^{\mathrm{a}}$ & 0.21 & $7.98^{a}$ & 0.13 & $7.83^{\mathrm{a}}$ & 0.40 & $7.58^{a}$ & 0.34 \\
\hline $\begin{array}{c}\text { L3 } \\
\text { implant }\end{array}$ & $9.77^{\mathrm{a}}$ & 0.12 & $9.60^{\mathrm{a}}$ & 0.17 & $9.52^{\mathrm{a}}$ & 0.45 & $9.27^{\mathrm{a}}$ & 0.50 & $7.47^{\mathrm{b}}$ & 0.35 & $7.25^{b}$ & 0.40 & $7.02^{b}$ & 0.36 & $6.90^{\mathrm{b}}$ & 0.36 \\
\hline p-value & \multicolumn{2}{|c|}{$0.050 \mathrm{~ns}$} & \multicolumn{2}{|c|}{$0.062 \mathrm{~ns}$} & \multicolumn{2}{|c|}{$0.082 \mathrm{~ns}$} & \multicolumn{2}{|c|}{$0.072 \mathrm{~ns}$} & \multicolumn{2}{|c|}{$0.027 *$} & \multicolumn{2}{|c|}{$0.015^{*}$} & \multicolumn{2}{|c|}{$0.020 *$} & \multicolumn{2}{|c|}{$0.021 *$} \\
\hline
\end{tabular}

Superscripts with different capital letters indicate statistically significance difference within the same column. *; significant ( $p \leq 0.05) \quad n s ;$ non-significant $(p>0.05)$ 
When comparing the mean bone height changes for each of the three implants between the two group of patients at the different follow up intervals, it was found that there was a statistically significant difference in the mean bone height changes between the two groups of patients, in the second group of patients a greater decrease in the mean bone height changes was recorded for all three implants in all of the different follow up intervals when compared to the first group of patients.

For implant R3, there was a general decrease in the mean bone height in both groups during all of the follow up intervals. When comparing both groups of patients, the second group have shown a greater statistically significant decrease in mean bone height changes $p<0.001$ during all of the follow up interval when compared to the first group of patient. In the first group of patients, the mean bone height recorded at the day of loading was $9.88 \mathrm{~mm} \pm 0.08$, then declined to $9.77 \pm 0.12$ after 3 month follow up, then $9.69 \pm 0.16$ after 6 month follow up, and $9.53 \mathrm{~mm} \pm 0.25$ after a 12 month follow up. The mean amount of mean bone loss during the 12 month follow up was $0.35 \mathrm{~mm}(9.88 \mathrm{~mm} \pm 0.08-9.53 \mathrm{~mm} \pm$ $0.25)$. While for the second group of patients the mean bone height was measured at delivery to be $8.18 \mathrm{~mm} \pm 0.20$, then after 3 and 6 month follow up it was recorded to be; $8.07 \pm 0.15,7.99 \pm 0.12$ while after 12 month follow up it have shown a decrease to be $7.83 \mathrm{~mm} \pm 0.15$, when comparing between the mean bone height recorded at delivery and after 12 month follow up, the amount of bone loss was calculated to be $0.35 \mathrm{~mm}$. For implant R3 the mean amount of bone loss was equal in both groups recording $0.35 \mathrm{~mm}$ after a 12 month follow up, despite that a statistically significant difference in mean bone height changes was shown to be present during each follow up interval between the two groups of patients for the 12 month follow up (Table 2).

For the implant at the mid line, the mean bone height changes have declined in both groups thought out the different follow up intervals, showing a statistically significant difference between the first and second group at the day of delivery and after 3 month follow up $p=0.021$, while after 6 month follow up $p=0.042$, and after 12 month follow up $p=0.016$. In the first group of patients the mean bone height have shown a decrease during all of the follow up intervals recording $9.20 \pm 0.46$ at the day of delivery, reaching $9.05 \pm 0.48$ and $8.87 \pm 0.45$ after a 3 and 6 month follow up. After a 12 month follow up the mean value of bone height was recorded as $8.67 \pm 0.32$, so when calculating the amount of mean bone loss during the 12 month follow up period it was $0.53 \mathrm{~mm}(9.20 \pm 0.46-8.67 \pm 0.32)$. While for the second group of patients mean bone height have shown a decrease during all follow

TABLE (2) The mean, standard deviation (SD) values of bone height changes in different groups of right canine implant within each time period.

\begin{tabular}{|c|c|c|c|c|c|c|c|c|}
\hline \multirow{4}{*}{ Variables } & \multicolumn{8}{|c|}{ Bone height changes } \\
\hline & \multicolumn{8}{|c|}{ Right canine implant (R3) } \\
\hline & \multicolumn{2}{|c|}{ At delivery } & \multicolumn{2}{|c|}{ After 3 months } & \multicolumn{2}{|c|}{ After 6 months } & \multicolumn{2}{|c|}{ After 12 months } \\
\hline & Mean & SD & Mean & SD & Mean & SD & Mean & SD \\
\hline Group 1 & $9.88^{\mathrm{a}}$ & 0.08 & $9.77^{\mathrm{a}}$ & 0.12 & $9.69^{\mathrm{a}}$ & 0.16 & $9.53^{\mathrm{a}}$ & 0.25 \\
\hline Group 2 & $8.18^{\mathrm{b}}$ & 0.20 & $8.07^{b}$ & 0.15 & $7.99^{b}$ & 0.12 & $7.83^{\mathrm{b}}$ & 0.15 \\
\hline p-value & \multicolumn{2}{|c|}{$<0.001 *$} & \multicolumn{2}{|c|}{$<0.001 *$} & \multicolumn{2}{|c|}{$<0.001 *$} & \multicolumn{2}{|c|}{$0.001 *$} \\
\hline
\end{tabular}

Superscripts with Different capital letters indicate statistically significance difference within the same column.

*; significant ( $p \leq 0.05) \quad n s ;$ non-significant ( $p>0.05)$, 
up intervals; at delivery it was $8.13 \pm 0.21$, after 3 month it recorded $7.98 \pm 0.13$, after 6 month a value of $7.83 \pm 0.40$ and reached after 12 month follow up a value of $7.58 \pm 0.34$. The mean amount of bone loss during the 12 month follow up was $0.55 \mathrm{~mm}$. Thus when comparing the mean amount of bone loss between the two groups it was found that a greater amount of bone loss was recorded in the second group $0.55 \mathrm{~mm}$ when compared to $0.53 \mathrm{~mm}$ in the first group (Table 3).

For Implant L3, in both groups of patients bone height changes have recorded a decrease with a statistically significant decline in the second group of patients when compared with the first group during the different follow up intervals, having $p<0.001$ at the day of delivery, and $p=0.001$ after 3 month follow up, and after 6 month $\mathrm{p}=0.002$, and reach- ing $p=0.003$ after a 12 month follow up. In the first group of patients mean bone height was recorded to be $9.77 \pm 0.12$ at delivery, then decreased to 9.60 \pm 0.17 after 3 month follow up, and then reaching $9.52 \pm 0.45$, and $9.27 \pm 0.50$ after a 6 month and 12 month follow up. The mean amount of bone loss throughout the 12 month follow up was recorded to be $0.50 \mathrm{~mm}$. While for the second group of patients the mean bone height has recorded a decrease during all intervals recording $7.47 \pm 0.35,7.25 \pm 0.40$, $7.02 \pm 0.36,6.90 \pm 0.36$ respectively at the day of delivery, after 3 month, after 6 month and after 12 month. So the mean amount of bone loss after a 12 month follow up was recorded to be $0.57 \mathrm{~mm}$. So when comparing the mean amount of bone loss between the two groups the second group of patient have recorded a greater amount of bone loss $0.57 \mathrm{~mm}$ compared to $0.50 \mathrm{~mm}$ in the first group (Table 4).

TABLE (3) The mean, standard deviation (SD) values of bone height changes in different groups of mid line implant within each time period.

\begin{tabular}{|c|c|c|c|c|c|c|c|c|}
\hline \multirow{4}{*}{ Variables } & \multicolumn{8}{|c|}{ Bone height changes } \\
\hline & \multicolumn{8}{|c|}{ Mid line implant } \\
\hline & \multicolumn{2}{|c|}{ At delivery } & \multicolumn{2}{|c|}{ After 3 months } & \multicolumn{2}{|c|}{ After 6 months } & \multicolumn{2}{|c|}{ After 12 months } \\
\hline & Mean & SD & Mean & SD & Mean & SD & Mean & SD \\
\hline Group 1 & $9.20^{\mathrm{a}}$ & 0.46 & $9.05^{\mathrm{a}}$ & 0.48 & $8.87^{\mathrm{a}}$ & 0.45 & $8.67^{\mathrm{a}}$ & 0.32 \\
\hline Group 2 & $8.13^{\mathrm{b}}$ & 0.21 & $7.98^{b}$ & 0.13 & $7.83^{\mathrm{b}}$ & 0.40 & $7.58^{\mathrm{b}}$ & 0.34 \\
\hline p-value & \multicolumn{2}{|c|}{$0.021 *$} & \multicolumn{2}{|c|}{$0.021 *$} & \multicolumn{2}{|c|}{$0.042 *$} & \multicolumn{2}{|c|}{$0.016^{*}$} \\
\hline
\end{tabular}

Superscripts with different capital letters indicate statistically significance difference within the same column.

*; significant $(p \leq 0.05) \quad n s ;$ non-significant $(p>0.05)$,

TABLE (4) The mean, standard deviation (SD) values of bone height changes in different groups of left canine implant within each time period.

\begin{tabular}{|c|c|c|c|c|c|c|c|c|}
\hline \multirow{4}{*}{ Variables } & \multicolumn{8}{|c|}{ Bone height Changes } \\
\hline & \multicolumn{8}{|c|}{ Left canine implant } \\
\hline & \multicolumn{2}{|c|}{ At delivery } & \multicolumn{2}{|c|}{ After 3 months } & \multicolumn{2}{|c|}{ After 6 months } & \multicolumn{2}{|c|}{ After 12 months } \\
\hline & Mean & SD & Mean & SD & Mean & SD & Mean & SD \\
\hline Group 1 & $9.77^{\mathrm{a}}$ & 0.12 & $9.60^{\mathrm{a}}$ & 0.17 & $9.52^{\mathrm{a}}$ & 0.45 & $9.27^{\mathrm{a}}$ & 0.50 \\
\hline Group 2 & $7.47^{\mathrm{b}}$ & 0.35 & $7.25^{b}$ & 0.40 & $7.02^{\mathrm{b}}$ & 0.36 & $6.90^{\mathrm{b}}$ & 0.36 \\
\hline p-value & \multicolumn{2}{|c|}{$<0.001 *$} & \multicolumn{2}{|c|}{$0.001 *$} & \multicolumn{2}{|c|}{$0.002 *$} & \multicolumn{2}{|c|}{$0.003 *$} \\
\hline
\end{tabular}

Superscripts with different capital letters indicate statistically significance difference within the same column. *; significant $(p \leq 0.05) \quad n s ;$ non-significant $(p>0.05)$. 
From all of the above results it could be shown that the three implants in the second group of patients have recorded greater significant bone height changes in all of the follow up intervals when compared to the first group of patients (figure 5).

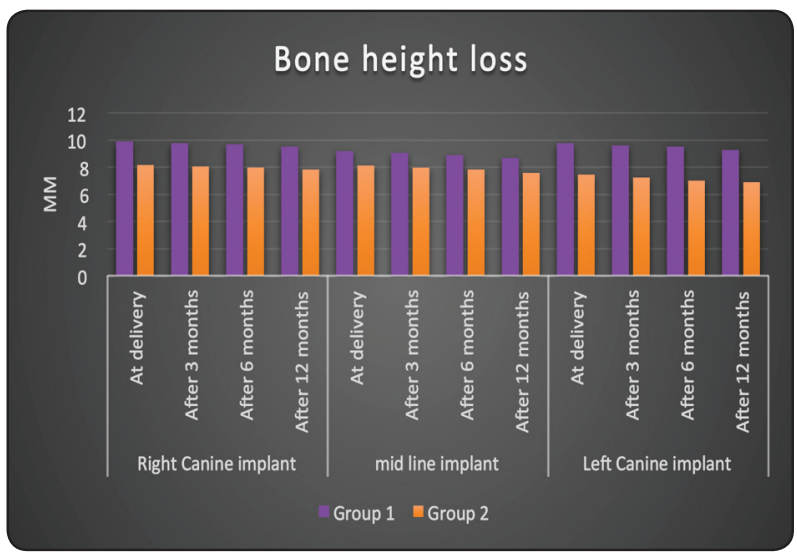

Fig. (5): Bar chart representing bone height changes in different groups of all implants within each time period.

\section{DISCUSSION}

Mastication forces and excessive loads would result in biomechanical complications that may eventually lead to failure of the installed implants ${ }^{22,23}$. The number and location of the implants supporting an overdenture may vary but is of importance when considering the distribution of forces to the underlying implants. Many studies have proven that three or four implant retained overdenture is a successful treatment option for the edentulous mandible. Installation of more than two implants in the edentulous mandible would result in an angular relation rather than a straight line relationship between the implants, as the most anterior implant would prevent intrusion of the anterior part of the denture in a tissue ward movement ${ }^{13}$. This would explain the results of our present study, in the first group of patients where the implants were placed with a fixed inter-implant distance of $40 \mathrm{~mm}$, and the implant installed in the mid line was more anterior to the two distal implants resulting in tripod distribution, this implant in the mid line have recorded the greatest decrease in mean bone height changes after a 12 month follow up, as it have shared a greater part of the forces than the other two distal implants, due to the intrusive forces that was falling on this implant to prevent the tissue ward movement of the anterior part of the denture.

One of the most important criteria for the success of any prosthesis is the even distribution of the stresses to the underlying implants or abutments. The mode of load transfer and stress distribution has been proven to be in direct relation to the distance from the point of loading ${ }^{30}$. A study have concluded that the implant closer to the load application will primary absorb most of the load ${ }^{31}$. Based on this assumption the most distal implant on each side acts as a fulcrum therefore the amount of force is magnified by the length of the cantilever which acts as a lever ${ }^{32}$. So the forces exerted on the implant is estimated according to the lever relationship as follows;

The above diagram (Fig 6) would help to interpret the results of the present clinical trial. In the first group of patients all implants have shown a decrease in bone height indicating an amount of bone loss after a 1 year follow up, with no statistically significant difference between the three implant in the all of the different follow up intervals, and the implant in the mid line showing the greatest bone loss when compared to the more distal implants. An explanation for this result is that the inter-implant distance has been fixed to all implants which is equal to $40 \mathrm{~mm}$, so the length of the lever arm has been constant and so the moment on either side of the point of rotation have been counter balanced by the implant in the mid line, which has received intrusive forces resulting in greater bone height changes when compared to the two distal implants.

When evaluating the mean amount of bone loss after a 12 month follow up for the first group of patients it was found that the greatest amount of bone loss was found in the implant in the mid line $0.53 \mathrm{~mm}$, followed by the implant in the left canine $0.50 \mathrm{~mm}$, and the least was in the implant in the 


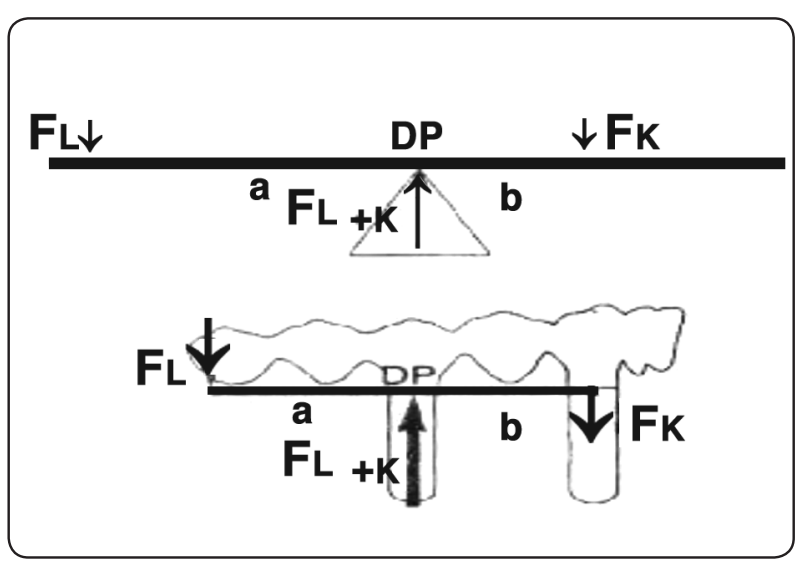

Fig (6): Showing the balance of forces using an example of a fulcrum. Force (FL) and counter force (FK) are in balance if the moment given by the force (FL) times a lever arm (a) is identical to the moment given by the counterforce (FK) times the lever arm (b). The sum of forces is equal to zero and the moment on either side of the point of rotation DP is counterbalanced (load force FL $\mathrm{X}$ lever arm $\mathrm{a}=$ force FK $\mathrm{x}$ lever arm $\mathrm{b}$ ). The most distal implant receives intrusive force FL+FK, while the next implant receives extrusive forces FK. (Book of removable partial dentures on osseointegrated implants)33

right canine $0.35 \mathrm{~mm}$. The reason for this is that the implant in the mid line has shared a great part of the load so resulted in the greatest amount of bone loss when compared to the two other implants. While when comparing the right and left canines, they are both considered to be terminal abutments and the intrusive forces $(\mathrm{FL}+\mathrm{FK})$ falling on them would be influenced by the distance from load application and by the stresses transmitted from the telescopic retainer during prosthesis movement. The only explanation that the implant at the left canine was subjected to more bone loss than the implant at the right canine, may be patients had a tendency to chew more on the left side than the right side so the implant being closer to the load received more stresses thus experiencing more bone $\operatorname{loss}^{31}$.

In the second group of patients the implants on the right side were installed in the canine area and the central incisor area having an interimplant distance of $15 \mathrm{~mm}$, while the implant on the left side was installed at an inter-implant distance of $40 \mathrm{~mm}$ from the central incisor area, all telescopic retainers were of the same design as in the first group of patients. All implants in this group of patients have shown a decrease in bone height, implants with an inter-implant distance of $15 \mathrm{~mm}$ have shown no significant difference in the bone height changes while the implant on the left side with an interimplant distance of $40 \mathrm{~mm}$ have shown the greatest decrease in bone height changes with a statistically significant difference when compared to the implants of a $15 \mathrm{~mm}$ inter-implant distance. The reason for such results is that the implant with the greatest inter-implant distance have resulted in an increase in the length of lever arm and this terminal implant would receive intrusive forces (FL+FK) as shown in the diagram above (Fig 6), so as the lever arm length increases this would consequently result in an increase in the moment load falling on the implant as moment load = force magnitude $\mathrm{x}$ moment $\mathrm{arm}^{32}$, this would result in bone height changes after a one year follow up. While on the right side the interimplant distance is smaller $15 \mathrm{~mm}$ compared to that on the left side $40 \mathrm{~mm}$, so the moment of forces falling on the implants on the right side will be smaller due to a decrease in the length of lever arm than that on the left side, resulting in less bone height changes compared to the implant on the left side with a $40 \mathrm{~mm}$ inter-implant distance. That would also clearly explain the reason that the mean amount of bone loss after a one year follow up in the second group of patients was greater in implant on the left side $(0.57 \mathrm{~mm})$, followed by the implant in the mid line $(0.55 \mathrm{~mm})$ and the least was the terminal implant on the right side $(0.35 \mathrm{~mm})$.

When comparing between the three implants in the two group of patients there was a statistically significant difference in bone height changes for all implants after a 12 month follow up period, with a more significant decrease in the mean bone height in the second group of patients indicating more bone loss when compared to the first group of patients. The reason for this will be probably because of the 
difference in the interimplant distance between the implants in the two groups which have influenced the transfer of stresses, as the implants in the second group were not distributed evenly, this will increase the length of the lever arm, as the lever arm increases so will the moment directed to the implant increase as well, this increase in moment was interpreted as greater decrease in bone height and so more bone loss. An invitro study carried out by Tokar et al $2017^{34}$ have concluded as the interimplant distance between the implants decreased, this will decrease the stresses falling on the installed implants. Another explanation of the greater decrease in bone height changes in the second group of patient when compared to the first group of patients is that in the second group of patients, the uneven distribution of installed implants with the varied interimplant distance have resulted in a smaller AP spread ,when compared to the first group of patients which has an equal interimplant distance with a tripod distribution. The greater the AP spread between the center of the most anterior implant and the most distal aspect of the posterior implant the smaller the resulting loads on the implants from cantilevered force because of the stabilizing effect of the anteroposterior distance ${ }^{32}$.

The amount of bone loss in this clinical trial after a one year follow up is considered to be within the physiologic limit, indicating no excessive forces directed to the implants, as following the criteria of successful osseointegration ${ }^{27-29}$ of having $1.5 \mathrm{~mm}$ of bone loss within the first year of loading and the greatest amount of bone loss in the present study was recorded to be $0.57 \mathrm{~mm}$.

A conclusion could be drawn from the results of this study, that the interimplant distance will play an important role in the transfer of stresses to the implants, an even distribution of implants with a fixed interimplant distance have proven to transfer less stresses to the underlying implants when compared to uneven interimplant distance. Within limitations of this study the uneven distribution of implants resulted in a more significant amount of bone loss around the three installed implants when compared to the even interimplant distribution, despite the fact that the mean amount of bone loss was within the acceptable physiologic limit in both groups.

The literature doesn't provide enough evidence concerning the influence on the interimplant distance on the transfer of stresses, thus to reach to a more definitive conclusions more researches should be carried out with a greater sample size and longer follow up periods.

\section{REFERENCES}

1- Thomason JM, Feine J, Exley C., et al. Mandibular two implant supported overdentures as the first choice standard of care of edentulous patients-the York Consensus Statement ,Br Dent J 2009;207:185-186.

2- Thomason JM, Kelly SA, Bendkowski A, Ellis JS. Two implant retained overdentures-A review of the literature supporting the Mc Gill and York Consensus Statements. J Dent 2012;240:22-34

3- Manal A. Awad, James P., Lund E. D., Jocelyne S. Feine. Comparing the efficacy of mandibular retained overdentures and conventional dentures among middle aged edentulous patients: satisfaction and functional assessment. Int J Prosthet 2003; 16:117-122.

4- Setz JM, Wright PS, Ferman AM. Effects of attachment type on the mobility of implant-stabilized overdentures-An invitro study. Int J Prosthodont 2000;13:494-499.

5- Batenburg RH, Meijer HJ, Raghoebar GM, Vissink A. Treatment Concept for mandibular overdentures supported by endosseous implants: A Literature review. Int J Oral Maxillofac Implants 1998;13:359-545.

6- Feine JS, Carlsson GE, Awad MA. The McGill consensus statement on overdentures. Quintessence Int 2003;34:78-9.

7- Feine JS, Carlsson GE, Awad et al. The McGill Consensus statement on overdentures. Montereal, Quebec, Canda. May 24-25, 2002.Int J Prosthodont 2002;15:413-414.

8- Batenburg RH, Raghoebar GM, Van Oort RP, Heijdenrijk K, Boering G. Mandibular overdentures supported by two to four endosteal implants. A Prospective, Comparative Study. Int J Oral MaxilloFac Surg 1998; 27:435-439. 
9- Celik G, Uludag B. Effect of the number of supporting implants on mandibular photoelastic models with different implant-retained overdenture designs. J Prosthodont 2014;23:374-380.

10- Wismeijer D, Van Waas MA, Vermeeren JI, Mulder J, Kalk W. Patient Satisfaction with implant supported mandibular overdentures. A Comparison of three treatment strategies with ITI dental implants. Int J Maxillofac Surg 1997; 26:263-267.

11- Uludag B., Polat S. Retention characteristics of different attachment systems of mandibular overdenture retained by two or three implants. Int J Oral Maxillofac Implants 2012; 27:1509-1513.

12- Naert I, Gizani S, Vuylsteke M, Van Steenberghe D. A 5 year prospective randomized clinical trial on the influence of splinted and unsplinted oral implants retaining a mandibular overdenture: Prosthetic aspects and patient Satisfaction. J Oral Rehabil 1999; 26:195-202.

13- Ben-Ur Z, Gorfil C., Shifman A. Anterior implant-supported overdentures. Quintessence Int 1997; 27:603-6.

14- Sadig WM. Special technique for attachment incorporation with an implant overdenture. J Prosthet Dent 2003; 89:93-6.

15- Hoexter DL. Osseous regeneration in compromised extraction sites: a ten year case study. J Oral Implantol 2002; 28(1):19-24.

16- Okhubo C., Sato J., Hosoi T., Kurtz KS. O ring attachments for transitional implant retained overdentures $\mathrm{J}$ Prosthet Dent 2004; 91:195-7.

17- Mericske-Stern RD, Taylor TD, Besler U. Management of the edentulous patient. Clin Oral Implants Res 2000; 11:108-25.

18- Heckmann SM, Winter W., Meyer M., Weber HP., Wichmann MG. Overdenture attachment selection and loading of implant and denture bearing area. Part 1: in vivo verification of stereolithographic model. Clin Oral Implants Res 2001; 12:617-623.

19- Langer A. Telescope retainer for removable partial dentures. J Prosthet Dent.1981a; 45:37.

20- Langer A. Tooth supported telescopic restorations. J Prosthet Dent.1981 b; 44:515.

21- Frisch E, Ziebolz D, Ratka KP and Rinke S .Double Crown Retained Maxillary Overdentures: 5 Year Follow Up." Clin Implant Dent Relat Res 2005; 17: 22-31.

22- Gotfredsen K., Berglundh T., Lindhe J. Bone reactions adjacent to titanium implants subjected to static load of different duration. A study in the dog (III). Clin Oral Res 2001; 12:552-558.

23- Pesqueria A., Goiato M., Filho HG et al. Use of stress analysis methods to evaluate the biomechanics of oral rehabilitation with implants. J Oral Implantol 2014; 40:217-228.

24- Holmgren EP, Seckinger RJ., Kilgern LM., Mante F. Evaluating parameters of osseointegrated dental implants using finite element analysis -A two dimensional comparative study examining the effects of implant diameter, implant shape, and load direction. J Oral Implantol 1998; 24:80-88.

25- Michelinakis G., Barclay CW, Smith PW. The influence of interimplant distance and attachment type on retention characteristics of mandibular overdentures on 2 implants: initial retention values. Int J Prosthodont 2006; 19:507512.

26- Frederick DR, Caputo AA. Effects of overdenture retention designs and implant orientations on load transfer characteristics . J Prosthet Dent 1996;76:624-623.

27- Alberktsson T., Zarb G., Worthington P., Eriksson AR. The long term efficacy of currently used dental implants : A review and proposed criteria of success.Int J Oral Maxillofac Implants 1986;1:11-25.

28- Karoussis IK , Bragger U, Salvi GE , Burgin W, Lang NP. Effect of implant design on survival and success rates of titanium oral implants: A 10 year prospective cohort study of the ITI Dental implant system.Clin Oral Implants Res 2004;15:8-17.

29- Renvert S., Roos-Jansaker AM, Lindhal C, Renvert H., Rutger Persson G. Infection at titanium implants with or without a clinical diagnosis of inflammation. Clin Oral Implants Res 2007;18:509-516.

30- Assif D., Marshak B., Horowitz A. Analysis of load transfer and stress distribution by an implant supported fixed partial denture. J Prosthet Dent 1996;75:285-291.

31- Rangert B., Jemt T., Jorneus L. Forces and moments on branemark implants. Int J. Oral Maxillofac Implants 1989;4:241-247.

32- Misch Carl E. Book of dental implant Prosthetics. Elsevier Mosby Missorui 2005 pages 315, 317

33- Christian Basimo. Book of removable partial dentures on osseintegrated implants. Qunitessence publishing Co.1998, Germany.

34- Tokar Emre, Uludag Bulent, Karacaer Ozgul. Load transfer characterstics of three implant retained overdentures with different interimplant distances. Int J Oral Maxillofav Implants 2017,32:363-371. 